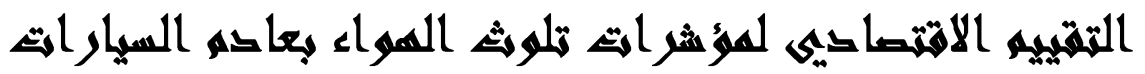

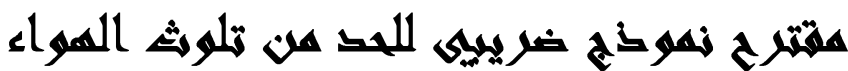

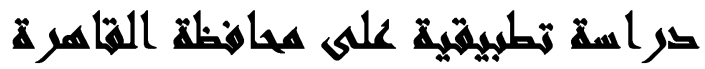

\section{[ $r \varepsilon]$}

محمود محمد الحويحى(')- سعيد توفيق عبيد(r)- نجلاء عمر محمود إبراهيم(r)

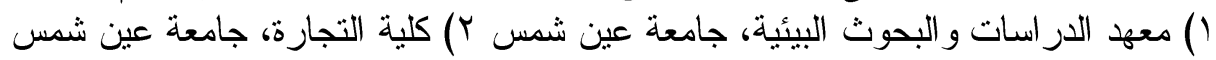
r) الثركة المصرية القابضة للبتروكيماويات

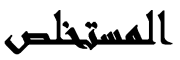

حظى موضوع البيئة و الدر اسات البيئية باهتمام المتحصصين والر أى العام فى العقدين

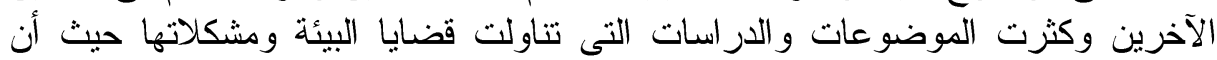
مسيرة العمل البيئى فى مصر تواجه بتحديات عديده اقتضت اتباع العديد من الأساليب

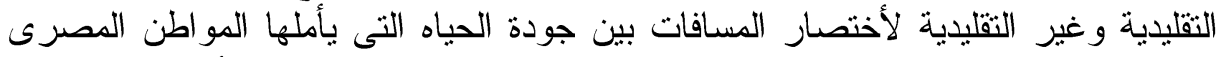

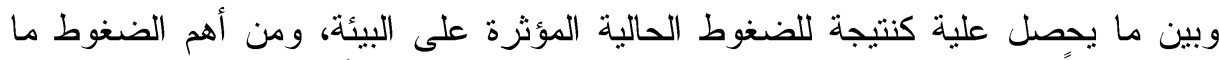

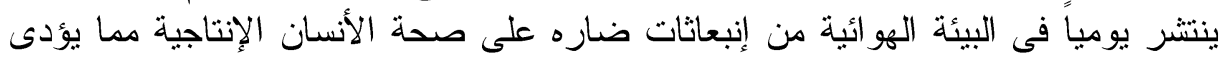

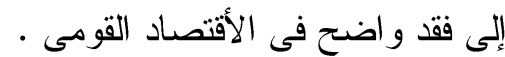

ومع تتامى حركة التتمية بالمجتمع المصرى بشى الافية الاقتصادى والاجتماعى بتزداد مصادر تلوث الهو اء المختلفة، فنزداد من آن لاخر عدد المصادر المتحركة (السيارات )

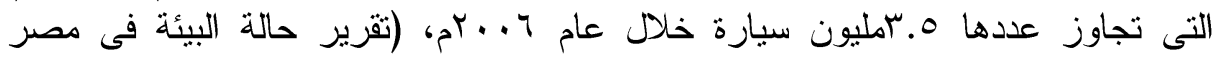

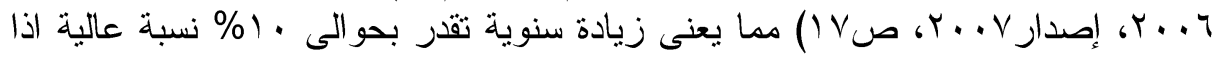

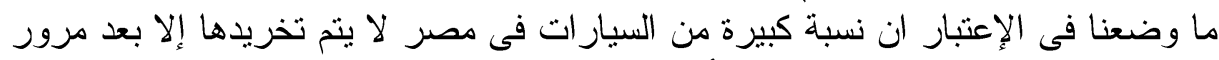

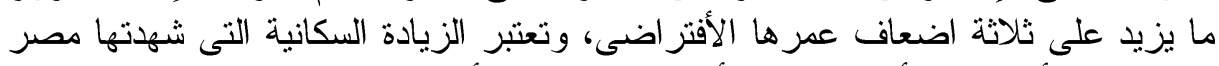

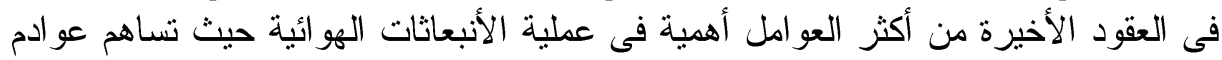
المركبات بنسبة جr\% من إجمالى الحمل السنوى للتلوث بالأثربة الصند الصدرية.

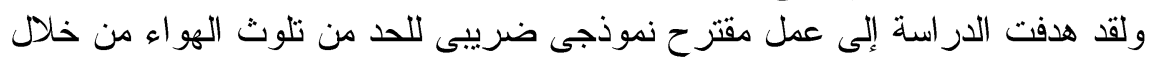

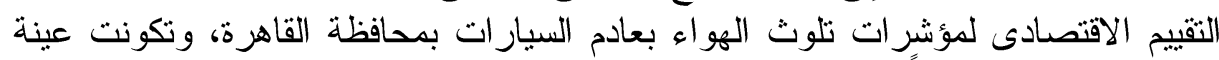

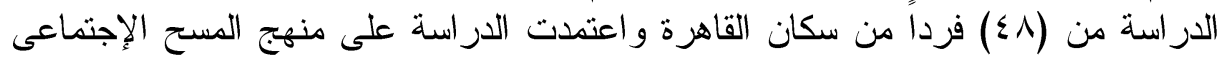

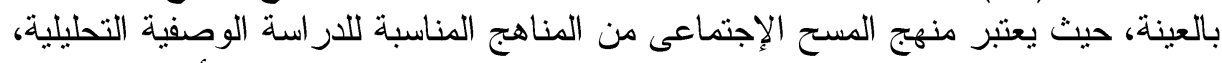
و استعان الباحثون باستمارة الاستقصاء و الملاحظة والمقابلة الثخصية، كما أعتمد الباحثون الثناج

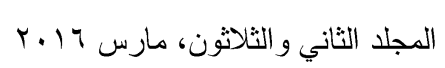


على بعض الأساليب الإحصائية منها إختبار ت test، والتكرارات و النسب. معامل

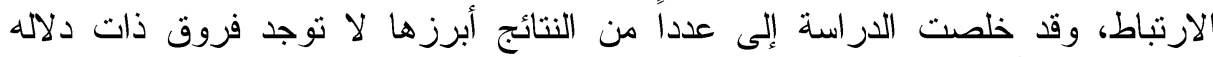

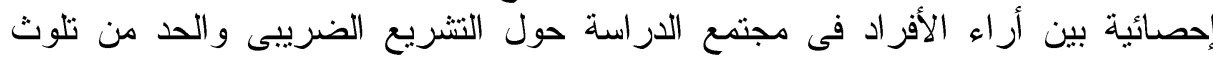

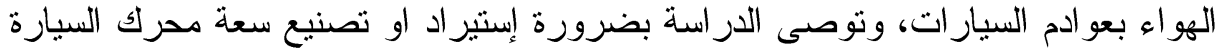

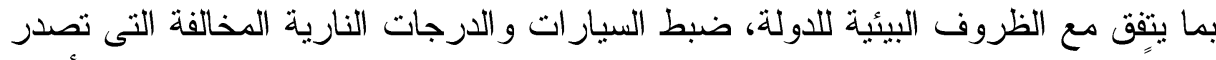

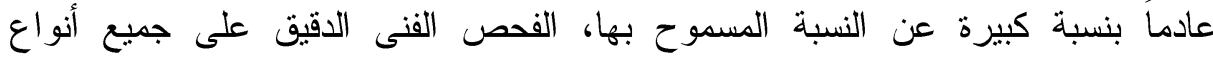

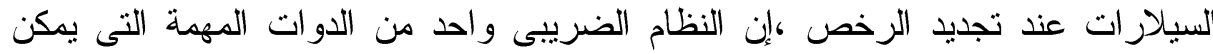

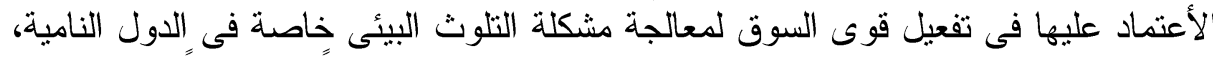
ومن ثم فإن مدخل السوق لمعالجة مشاكل التلوث البيئى يعتبر مدخلا إسترتيجيا.

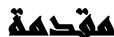

يعد النلوث صورة من صور الإخلال البيئي الذي يمكن أن بنتج عن أشياء عادية منل

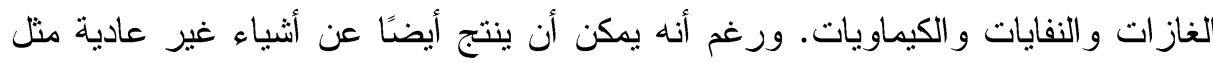

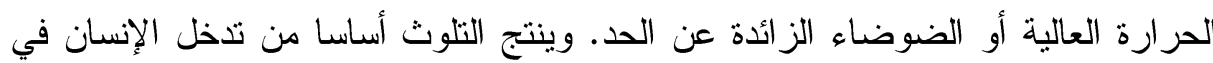

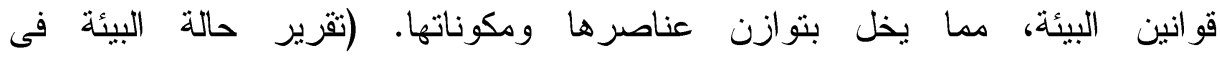

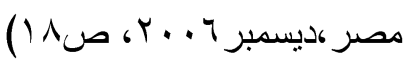
ويعد نصيب المواصلات في التسبب بنلوث الهواء في المدن الرئيسية، خاصة

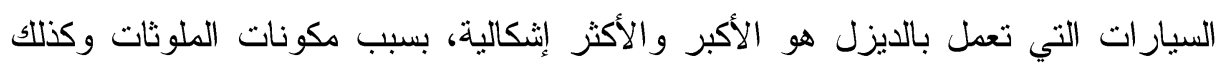

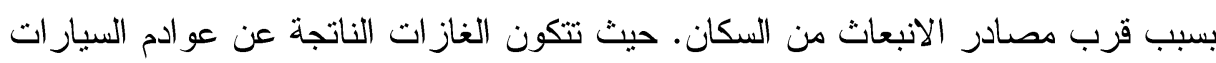

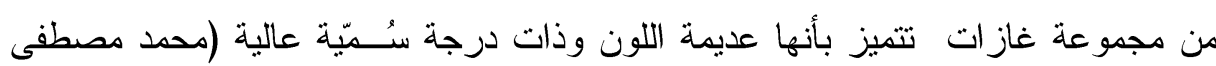

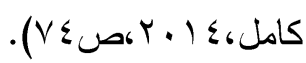

\section{أولا: الغازات الناتجة من عوادم السيارات اتهات:}

يعد غاز أول أكسيد الكربون (CO) من أكثر ملوثات الهواء في المدن وهو غاز شديد

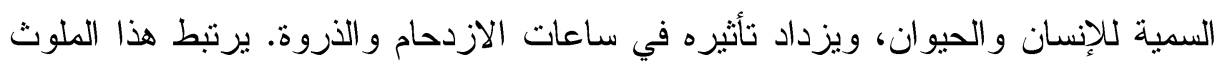

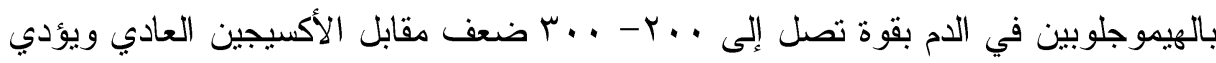
إلى صعوبات في نقل الأكسيجين إلى الأنسجة. وفي حالة التزكيز الخفيف يؤدي إلى الثعور 
بالنعاس، أوجاع الرأس و انعدام اليقظة. وفي حالة التركيز العالي- يؤدي إلى الوفاة نتيجة الاختناق. إن التعرض على مدى سنوات طويلة لمستويات منخفضة يزيد من شيوع النوبات القلبية. ويرجح بعض الباحثين إلى أن ارتفاع حوادث السير قد تعود إلى التعب والثون الإرهاق

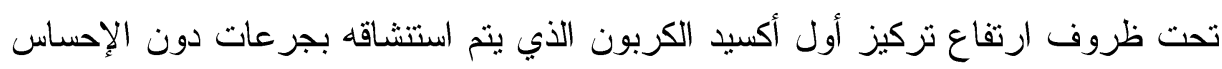

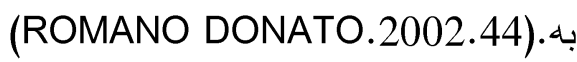
كما يعد غاز ثاني أكسيد الكربون (CO2) من أهم أسباب صعوبة التنفس و الثعور بالاختتاق، وحدوث مشاكل للأغشية المخاطية و التهاب القصبات الهو ائية. أما أكاسيد النيتروجين (Nox) فهى ملوثات تتتج بالأساس عن أكسدة النيتروجين

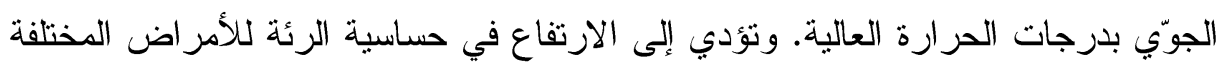

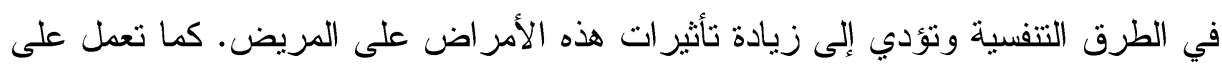
تهيج الغشاء المخاطي للعيون.

الهيدروكربونات (HC) و هى وقود غبر محترق أو محترق جزئياً. ينطلق بالأساس

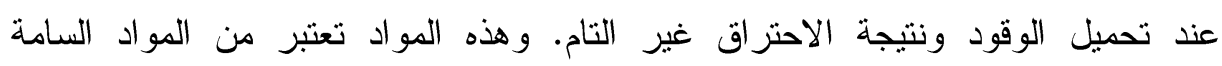

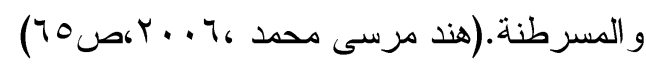
ثاني أكسيد الكبريت (CO2) يؤثر على الجهاز التنفسي فيحدث آلاماً في الصدر

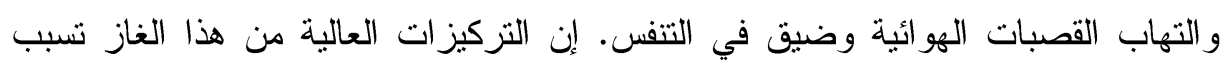

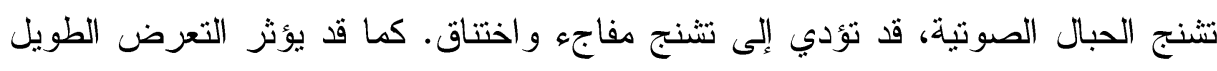

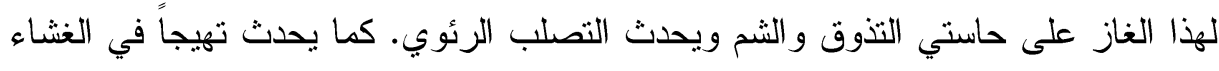
المخاطي للعيون وكذللك الجلد

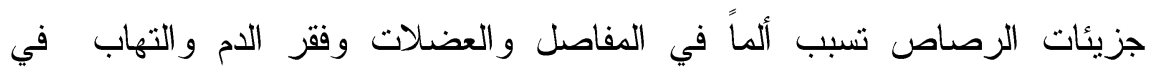

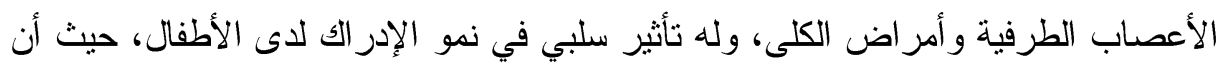

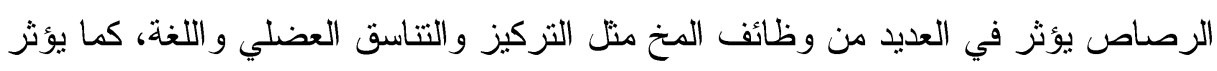

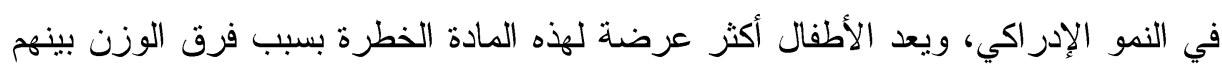

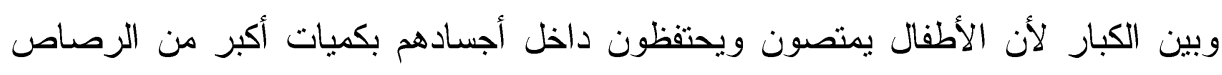


وينتج عن ذلك دخول الرصاص إلى أجسادهم أكثر بنسبة هب مرة من الكبار. يتسبب

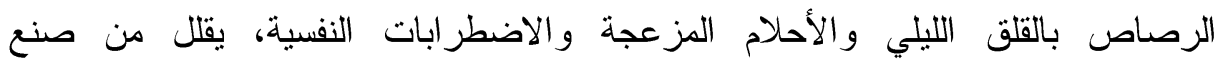
الهيموجلوبين في الجسم ويترسب في أنسجة العظام ويحل محل الكالسيوم. قد يؤدي

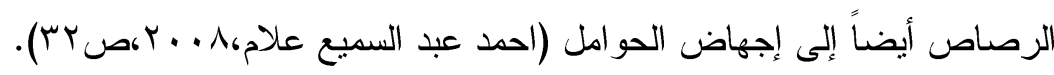
ثانيا: الجسيمات العالقة:

حدّدت دلائل عام ه . . الخاصة بجودة الهواء، لأول مرّة، قيمة مرجعية بخصوص الجسيمات. و الغرض من ذللك هو بلوغ أدنى نركيز ممكن من تللك الجسيمات. وينبغي، نظر اً لعدم تحديد أيّة عتبة فيما يخص الآثار الصحية الناجمة عن تلك الجسيمات، أن تمثّل القيمة الموصى بها هدفاً مقبو لاً يمكن بلو غه للحد من الآثار الصحية إلى أدنى مستوى ممكن

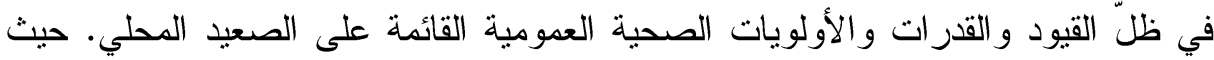

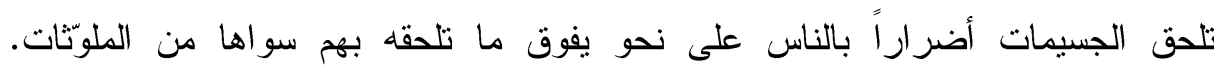

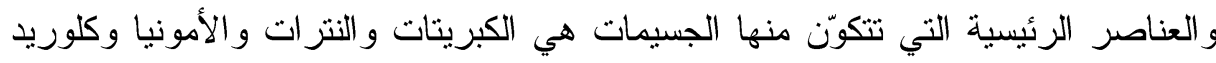

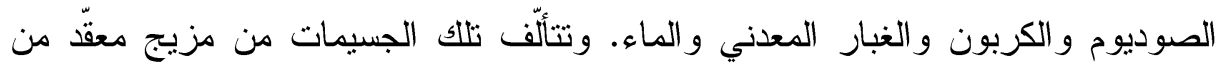

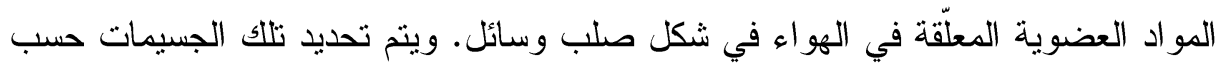

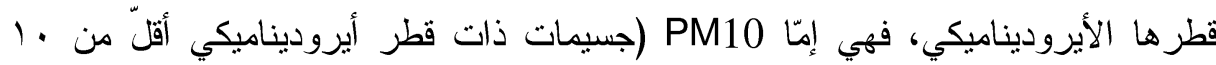
مكروغرامات) أو PM2.5 (جسيمات ذات قطر أيروديناميكي أقلّ من مر ب مكروغرام).

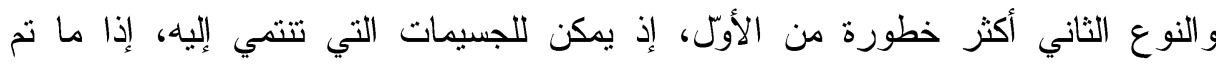

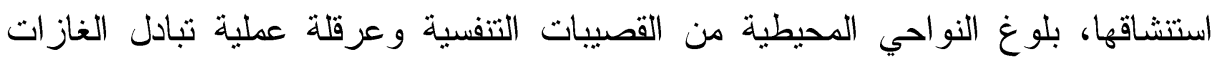

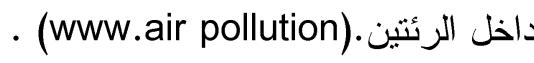

\section{هشفالة الثراسمة}

أن التلوث صورة من صور الإخلال البيئي ورغم أن التلوث يمكن أن ينتج من أثنياء

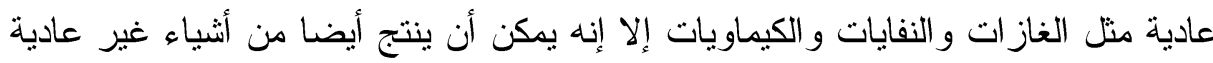

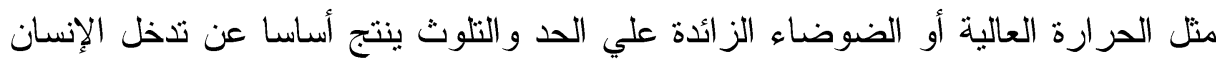

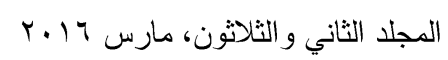


في قو انين البيئة التي منحها الخالق عز وجل، وإخلاله بتوازن عناصرها ومكوناتها وكانت

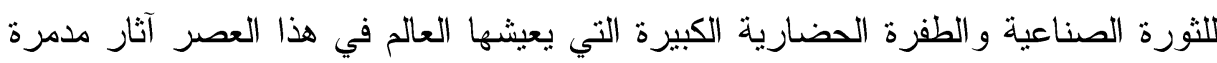

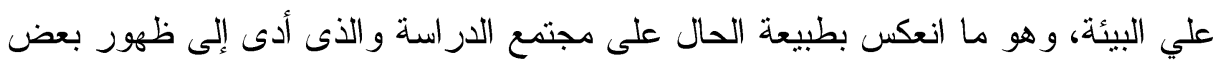

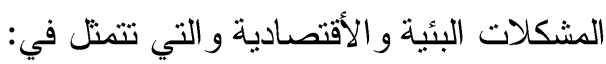
1- أن هناك العديد من مجالات تلوث الهواء وأن نسبة النلوث الناتجة من عو ادم السيارات

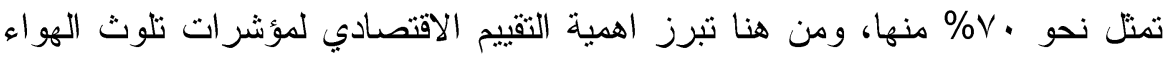

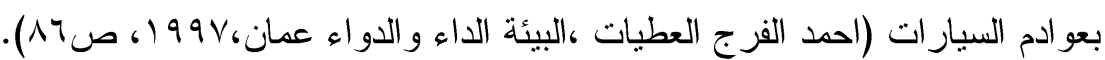
r- يوضح التزاث الفكري أنه لا توجد دراسات مطبقة اقتصاديًا تحدد الآثار الاقتصادية

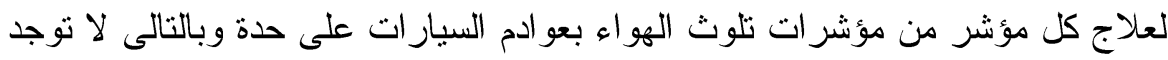
در اسة كاملة على التكلفة و العائد. ب- لابد من تدريب رجال المرور التدريب الكافي على كيفية قياس مؤشرات تلوث الهواء

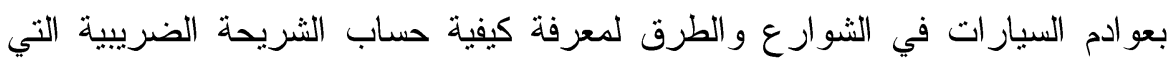
سوف تطبق حيث تطبق الضريبة حساب نوع المؤشر المنبعث من عو ادم السيارات.

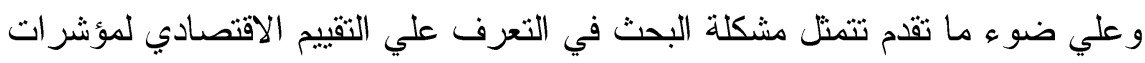
تلوث الهواء بعادم السيارات ومعرفة أوجه مظاهرها وتوضيح صورها وأو وأثنكالها وكيفية التغلب عليها، و الحلول المقترحة لحلها و التغلب على هذه المشكلات.

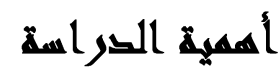

يعد قطاع النقل و المواصلات على أنو اعها وما يصدر عنه من عو ادم الدخان مصدر

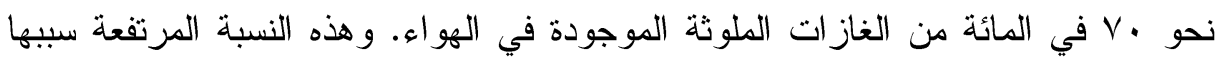

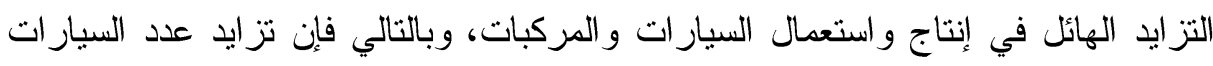
يعني زيادة في كمية الغازات المنبعثة من عوادم هذه السيارات وتحدد كمية الغازات

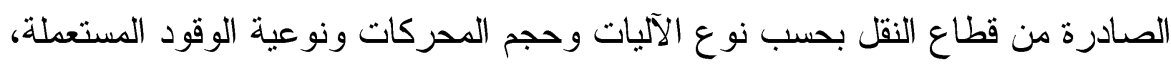


أما أهم الملوثات الهوائية الصادرة من قطاع النقل فهي غاز أول أكسيد الكربون

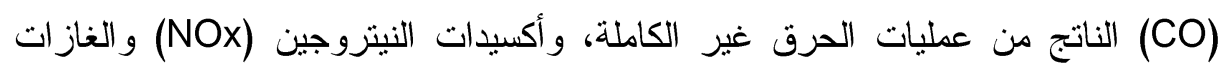

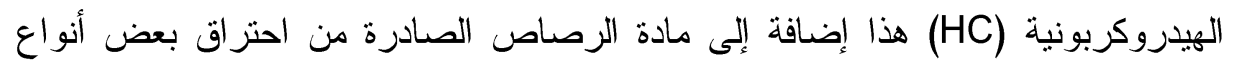

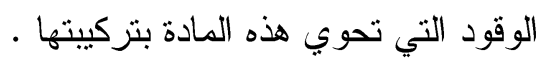

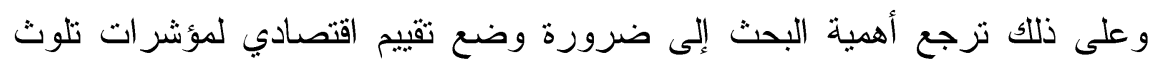
الهو اء بعادم السيارات وتحويل ذللك إلى مقترح نموذج ضريبي يفيد في الحد من عملية

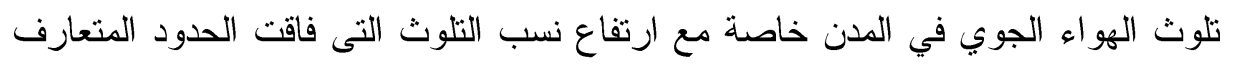
عليها عالميا.

\section{أهضا هيخ القر اسة}

يتمثل الهدف الرئيسي للار اسة في التقييم الاقتصادي لنلوث الهو اء بعوادم السيارات.

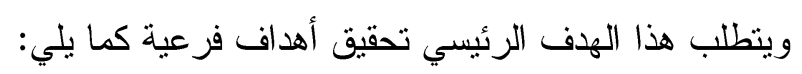

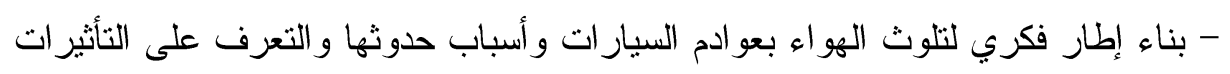
السلبية وكذلك التعرف على المؤشرات.

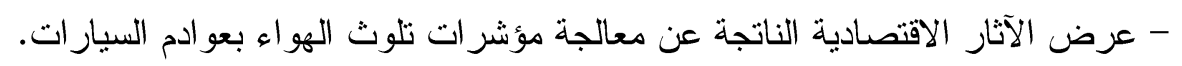

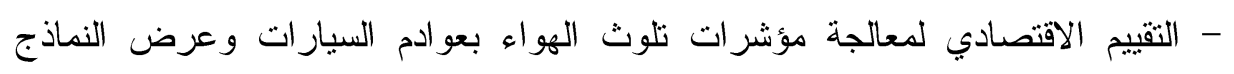
الأخرى المماتلة لحل مشكلة عو ادم السيارات سواء المصرية أو الأجنبية. - وضع نموذج ضريبي مقترح للحد من تلوث الهو اء بعو ادم السيار ات.

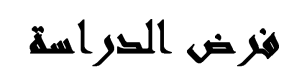

وفقا لمشكلة الدراسة يمكن صياغة فرض البحث بالثكل التالي " أنه لا توجد علاقة

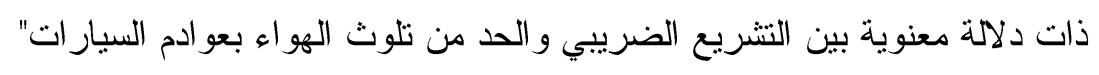




\section{مهزاهيم الكر اسة}

مفهوم تلوث الهواءع: يمكن تزيف تلوث الهواء بأنه الحالة التى يحتوى فيها الهواء على شو ائب ومواد عالقة من غير مكوناتة الأصلية، أو أن مكوناته الأصلية تكون عالية التركيز

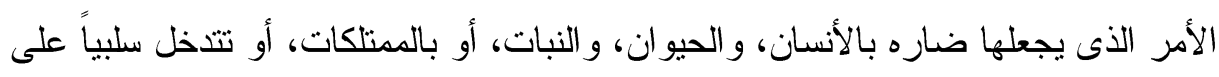

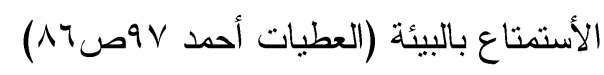

مفهوم التقيم الاقتصادى: التقييم الاقتصادي تقدير منخفض وفيه يتم جمع التكاليف المبانره وخسائر الانتاجيه مناجل حساب التكاليف الاجتماعيه الكليه و التي يمكن ملاحظتها لهابه في السوق ولكن لا تتضمن التكاليف الثخصيه منل الألم والمعاناه (برنامج جودة الهواء وليه التي تموله هيئة المعونة الامريكية للسياسات البيئية (USAID).

$$
\begin{aligned}
& \text { مفهوم النموذج الضريبي: } \\
& \text { ص =س + أ - ب حيث : } \\
& \text { ص : هي معدل الضريبة المقترح } \\
& \text { س : معدل الضريبة الحالي }
\end{aligned}
$$

أ : معدل يضاف الى المعدل الحالي في حالة ارتفاع النسبة المنبعثة لمؤشر تلوث

ب : معدل يخفض من المعدل الحالي في حالة انخفاض النسبة المنبعثة لمؤشر تلوث

$$
\text { الهو اء }
$$

\section{الإجر اعاتث المنهجية}

\section{نوع الاراسة والمنهج المستخدم:}

تدخل هذه الدر اسة فى نطاق الدراسات الوصفية لأنها أنسب الدراسات ملائمة لطبيعة الظاهرة المدروسة، حيث يتضمن هذا النوع من الدراسات دراسة الحقائق المتعلقة بطبيعة 
الظاهرة ،كما اعتمدت هذه الدراسة على منهج المسح الإجتماعى بالعينة حيث يعتبر منهج المسح الإجتماعى من المناهج المناسبة للار اسات الوصفية التحليلية. أدوات جمع البيانات:

عبارة عن استمارة استقصاء، والمقابلة الثخصية وأداة الملاحظة كأدوات لجمع الهع البيانات، وأستعان الباحثون ببعض الأساليب الإحصائية منها اختبار ت test، و التكرارات و النسب للتعرف على البيانات ذات الدلالة من خلال استخدام برنامج spss الإحصائى. وصف ادوات الار اسةة: الاستقصاء: اعتمد الباحثون في جمع بيانات الدراسة الميدانية على قائمة استقصاء تتفق مع

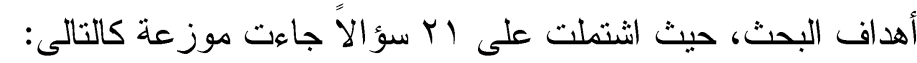
- الأسئلة من 1- - لقياس مدى الوعى البيئى لدى المجتمع المصرى.

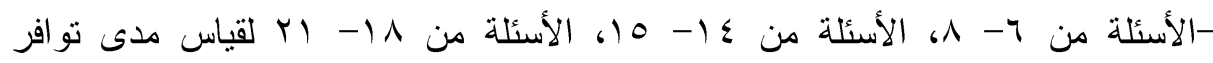
القوانين و اللوائح الخاصة بتطبيق الضريبة للحد من التلوث، ومدى استعداد المجتمع لتطبيق هذه اللو ائح و القو انين. - الأسئلة من ومدى الإدارك لمعنى تلوث الهو اء، و أسبابه الرئيسية، ونتائجة و آثاره.

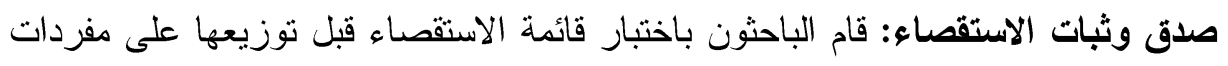
عينة البحث Pre Test. حيث قام الباحثون بتوزيع قائمة الاستقصاء على عينة استطلاعية لمعرفة مدى وضوح الأسئلة و ملاحظات المستقصي منهم. صدق المحكمين: حيث قام الباحثون بتوزيع الاستقصاء على بعض السادة الاساتذة لتحكيمة ومدى ملائمته للأهداف وفروض الدراسة. وقد استخدم الباحثون أسلوب المقابلة الثخصية في هذه المرحلة، عن طريق ملاحظة

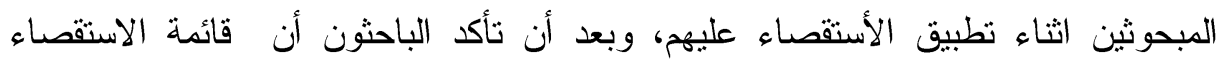
ملائمة لأهداف البحث قامت بصياغتها في الثكل النهائي و نوزيعها على عينة البحث، وبعد إعطائهم الوقت الكافى قامت بجمع هذه القو ائم ومر اجعتها وتحليلها. 
أ- المجال الجغرافي: ويقصد بالمجال الجغرافي هو النطاق المكاني لإجراء الدراسة وفى هذه الدراسة سوف يكون المجال الجغر افي لها محافظة القاهرة. ب- المجال البشرى: ويقصد بالمجال البشرى هو جمهور الدراسة وهم الأفرادالمقيمين بمحافظة القاهرة و تمثل هذه الفئة عينة الدراسة، قام الباحثون باختيار عينة من سكان

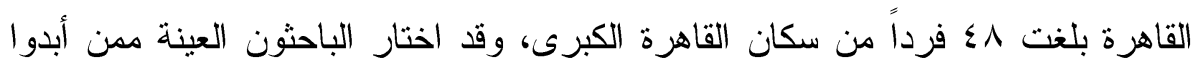

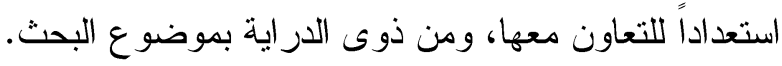

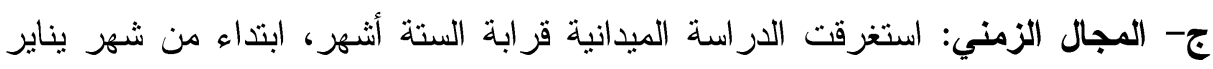
ـ ا • Y، وحتى نهاية شهر يونيو من نفس العام.

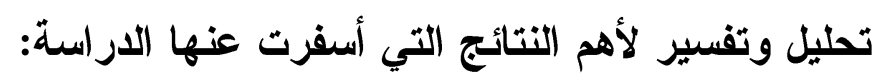

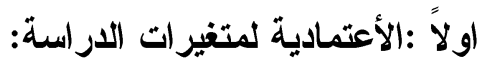

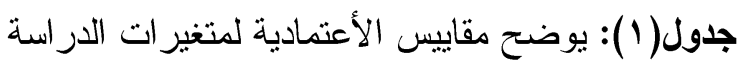

\begin{tabular}{|c|c|c|}
\hline قيمة الفا & أرقام الأسئلة & المتغيز ات \\
\hline$\% 4 \cdot . r$ & $0-1$ & الوعى البيئي لدى المجتمع المصرى \\
\hline$\% \vee \leqslant . \wedge$ & $\begin{array}{l}1-7 \\
10-1 \varepsilon \\
11-11\end{array}$ & 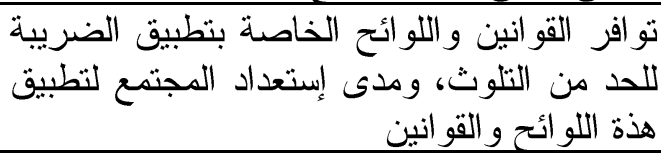 \\
\hline \%тr.। & $\begin{array}{c}15-9 \\
17-17\end{array}$ & 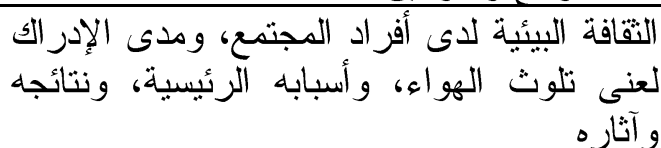 \\
\hline
\end{tabular}

يشير الجدول رقم (1) و الذى يوضح مقاييس الأعتمادية لمتغيرات الدر اسة، يتضح من

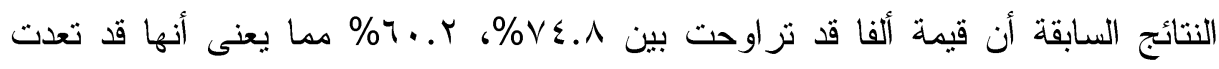

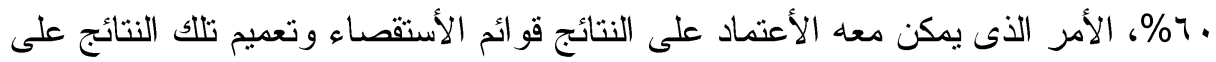
مجتمع الدر اسة. 
ومن خلال التحليل الإحصائى واختبار الفروض يتضح أن:

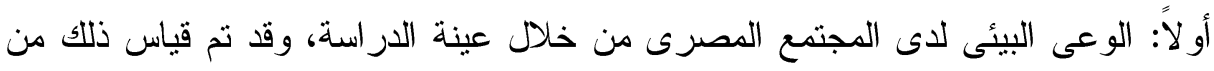

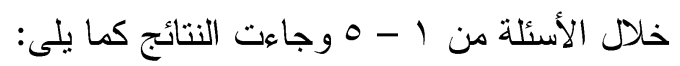

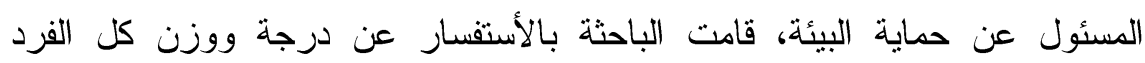

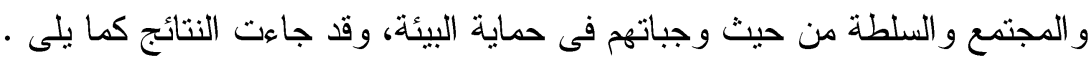
ثانياً : مسئولية وو واجب كل من الفرد و المجتمع والسلطة فى حماية البيئة

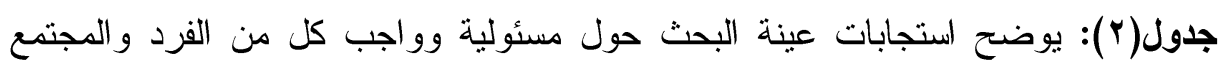
و السلطة فى حماية البيئة

\begin{tabular}{|c|c|c|c|c|c|}
\hline الإجمالى & $\begin{array}{c}1 \ldots-11 \\
\%\end{array}$ & $\% \wedge,-7)$ & $\% 4 \cdot-\{1$ & بيان & والو الجبأيتات \\
\hline$\sum \lambda$ & $r$ & 1. & 10 & عدد & \multirow[b]{2}{*}{ الفزد } \\
\hline$\ldots$ & $\varepsilon v .9$ & $r . . \wedge$ & rI.r & $\%$ & \\
\hline$\{\Lambda$ & 1 & YM & 19 & عدد & \multirow{2}{*}{ المجتمع } \\
\hline $1 \ldots$ & Y.1 & $01 . r$ & $r 9.7$ & $\%$ & \\
\hline$\varepsilon \wedge$ & 17 & $1 \varepsilon$ & 11 & عدد & \multirow{2}{*}{ السلطة } \\
\hline $1 \ldots$ & rr.r & r 9.4 & rv.o & $\%$ & \\
\hline
\end{tabular}
ثالثاً : الاحصاء الوصفى ونتائج الاختبار

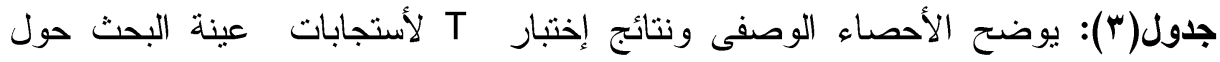
مسئولية وواجب كل من الفرد والمجتمع و السلطة فى حماية البيئة

\begin{tabular}{|c|c|c|c|c|c|c|}
\hline الترتيب & الدالاه & المنوية & TEST & إنحراف & المرجط & و المسئوليات \\
\hline 1 & داله & $\ldots \ldots$ & $0 . r Y q$ & IV.V & $\% \vee r . r$ & الفرد \\
\hline$r$ & غبر دالله &. .11 . & 1.74 & 1.17 & $\%$ \%r.o & المجتمع \\
\hline$r$ & داله & $\ldots .1$ & r.VrA & IV.. & $\% 79 . r$ & السلطة \\
\hline
\end{tabular}

$$
\text { يتضح من الجدولين السابقين ما يلى: }
$$

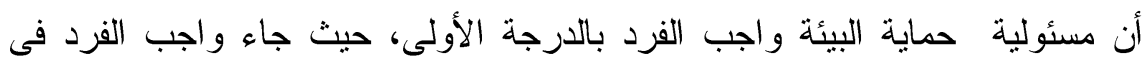

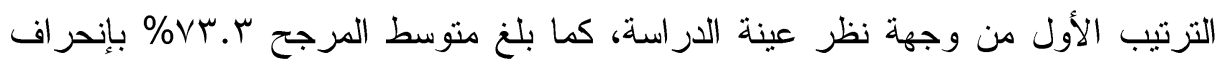




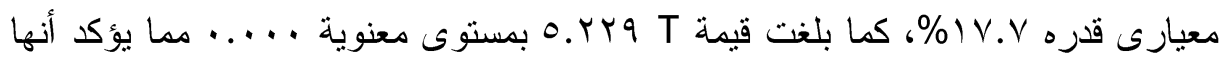

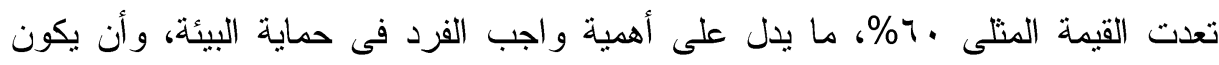
الفرد محور الأهتمام لدى الجهات المسئولة بحماية البيئة.

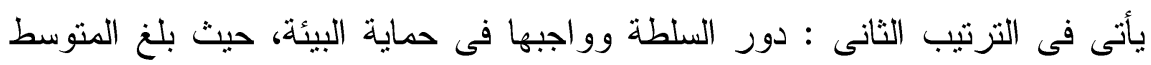

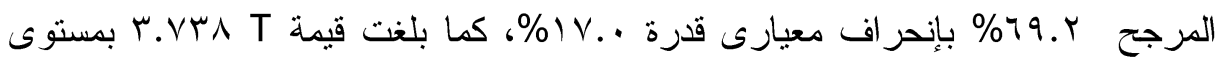

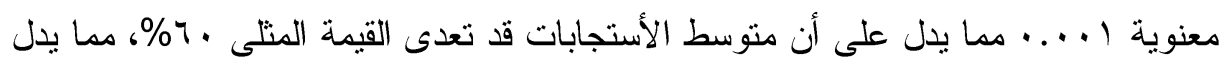
على أهمية وواجب السلطة فى حماية البيئة، وذلك لن السلطة تملك الأجهزة المختصة

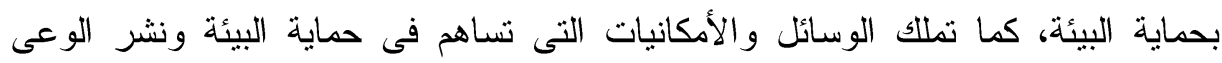

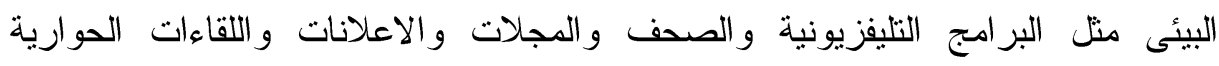
....الخ، كما تملك سن القو انين و التشريعات التى تؤدى إلى حماية البيئة.

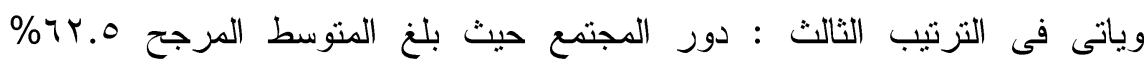

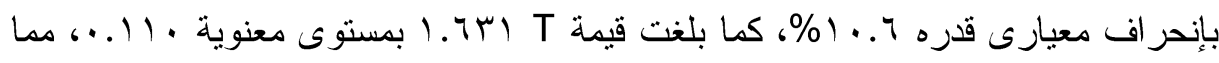

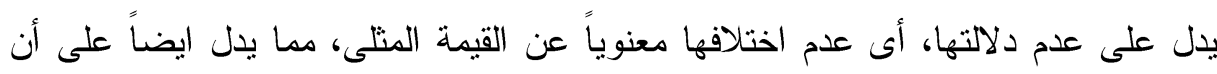

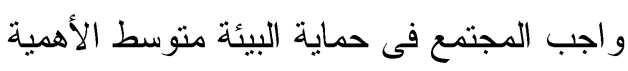

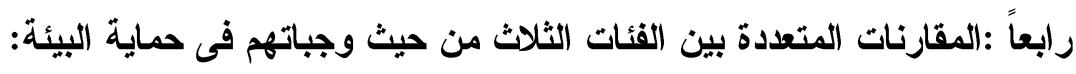

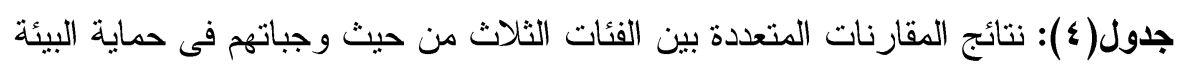

\begin{tabular}{|c|c|c|c|}
\hline السلطة & المجتمع & الفرد & الفئات \\
\hline $\begin{array}{l}\% \varepsilon .1 V \\
. .1 \wedge \wedge\end{array}$ & $\begin{array}{c}\left({ }^{*}\right) \% 1 \cdot . \wedge r \\
\ldots . .1\end{array}$ & & الفرد \\
\hline \multirow[t]{2}{*}{$\begin{array}{c}-\left({ }^{*}\right) \%{ }^{\circ} . .7 \mathrm{~V} \\
\ldots . \mathrm{rq}\end{array}$} & & & المجتمع \\
\hline & & & السلطة \\
\hline
\end{tabular}

يشير الجدول رقم (ع) و الذى يوضح نتائج المقارنات المتعددة بين الفئات الثلاث من حيث وجباتهم فى حماية البيئة، حيث يمثل السطر الأول فروق الأستجابات (استجابات بئن المتغير الوصفى - استجابات المتغير العمودى)، و السطر الثانى يوضح مستوى المعنوية -

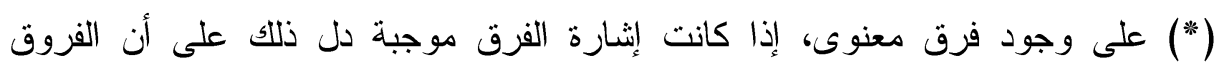

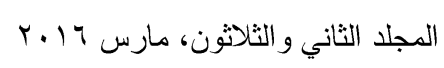


والأختلافات لصالح المتغير الصفى، أما إذا كانت إثارة الفرق سالبه دل ذلك على أن الفروق والأختلافات لصالح المتغير العمودى. ويتضح من الجدول السابق ما يلى:

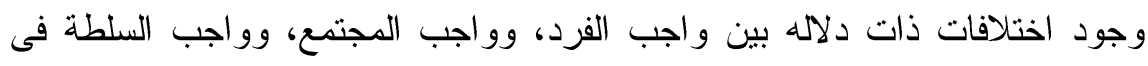
حماية ابيئة، وكانت هذه الفروق و الأختلافات لصالح السلطة، حيث بلغت فروق دون الأستجابات

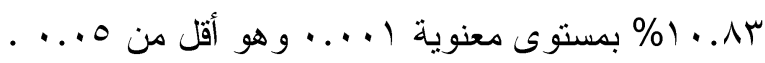

وجود اختلافات ذات دلاله بين واجب المجتمع، وواجب السلطة فى حماية البيئة،

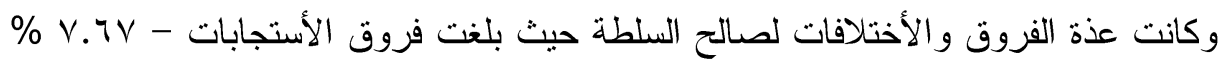

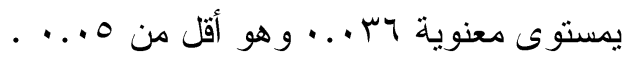
لم توجد فروق ذات دلاله بين واجب الفرد وواجب السلطة فى حماية البيئة، حيث

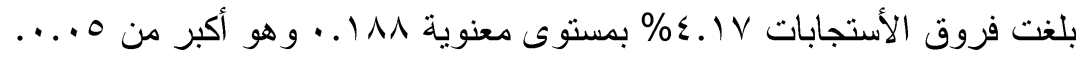
نلخص من ذلك إلى أهمية واجب كل من الفرد و السلطة فى حماية البيئة، ثم ياتى دور

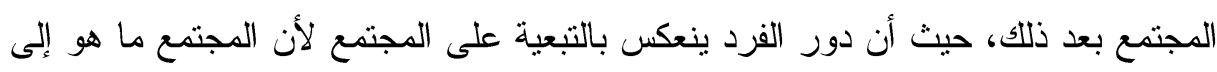
مجموعة الأفر اد الذين يعيشون فيه.

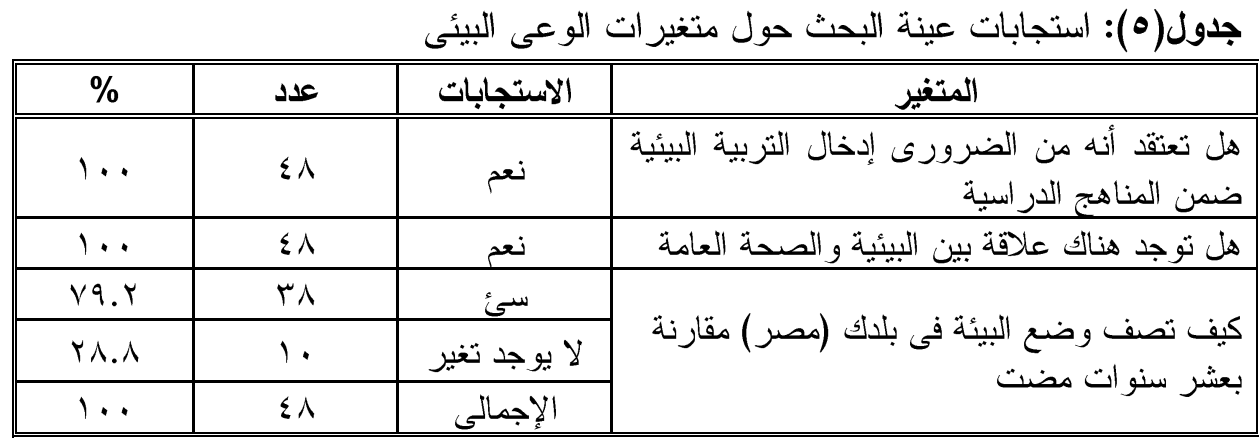

يتضح من الجدول السابق أن جميع افراد عينة البحث بنسبة . . 1\% يعتقدون أنه من

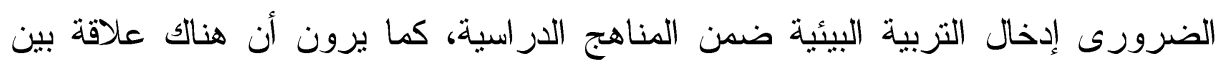
البيئة و الصحة العامة مما يدل على إدر الك عينة الدر اسة لأهمية التربية البيئية، و علاقة البيئة بالصحة العامة . 
كما وصفت نسبة Y.Y م من عينة البحث وضع البيئة فى (مصر) مقارنة بعشر

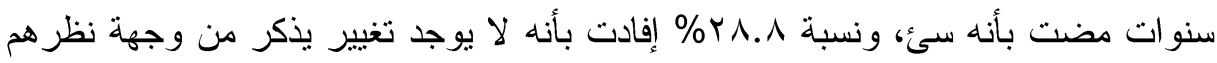

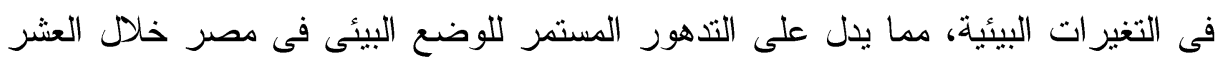

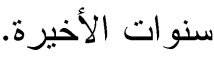

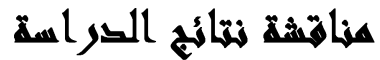

- توصلت الدراسة إلى أن هناك أسباب سلبية أدات إلى تلوث الهو اء بعادم السيارات و إذا تم إتباع ماسبق من خلال الوصول إلى تحقيق تحسن فى جودة الهواء فأن القيمة الحالية للمكاسب المخصومة من المدخرات الاقتصادية فى المستقبل، وفقاً لتحسن جودة الهواء هى أكبر بكثير بالنسبة للغبار عن أكسيد الكبريت أو الرصاص، حيث أن أكثر من 90\%

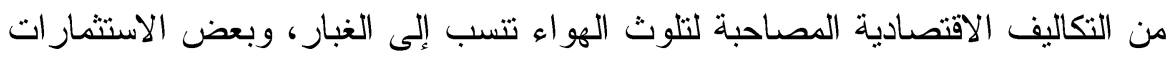

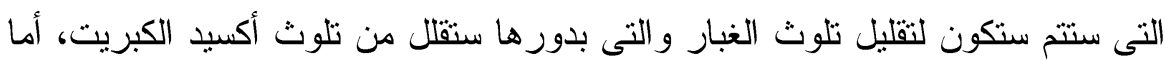
التذخلات لتقليل تلوث الرصاص ستكون حصرياً بالنسبة لأفران صهر المعادن بالقاهرة

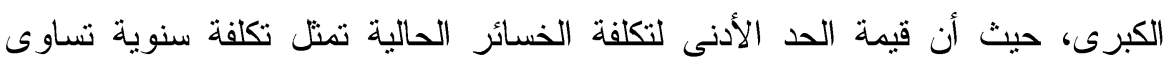

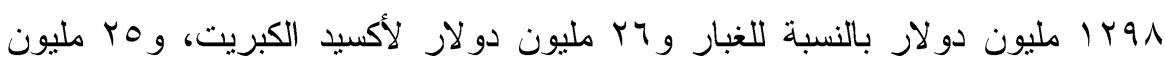

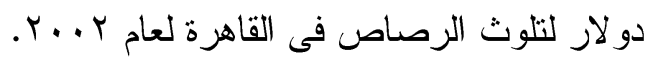

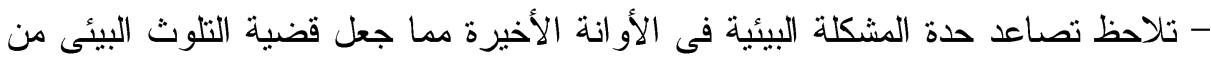

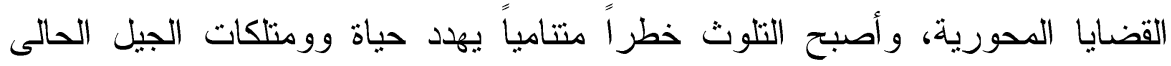

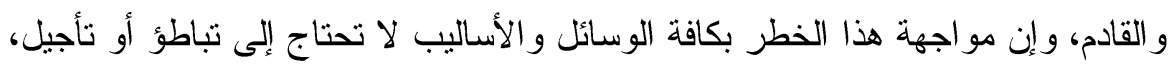
ومما لا شك فيه الأن أن النظام الضريبى الجديد يعد أحد هذه الوسائل و الأساليب إن لم إلى إلى

$$
\text { يكن أهمها. }
$$

- توصلت الدراسة إلى أن إستراتيجية التتمية التى تعتمدها أغلب الدول النامية فى الوقت

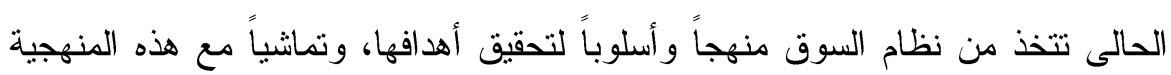
فى إدارة الاقتصاد فإن الأعتماد على مدخل السوق فى معالجة مشاكل التلوث البيئى يعد البه

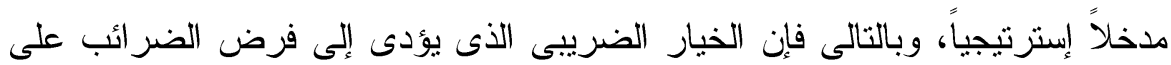

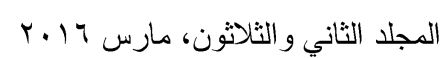


التلوث ومظاهر الأذى البيئى الأخرى، كفيل بأن يدفع الأفراد والمنشآت الملوثه

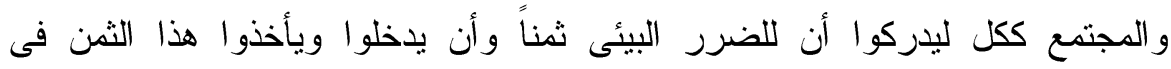

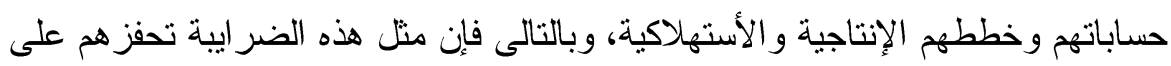
تخفيض الأضرار البيئية لأدنى حد ممكن. - توصلت الدراسة إلى أن النظام الضريبى البيئى لا يؤدى إلى منع تلوث البئ البيئة تماماً و إنما

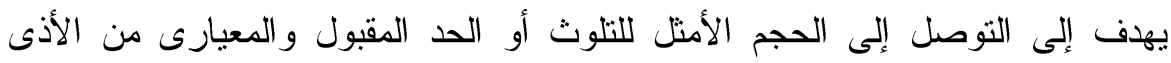
البيئى الذى يمكن قبولة فى ضوء حساب (النفقات - المنافع) لسياسة حماية البيئة.

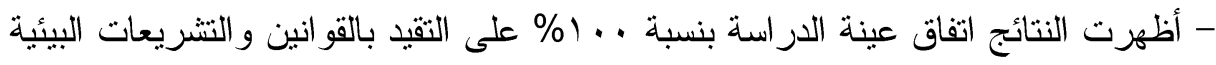
المشددة ، و الأستعداد لدفع الضر ائب البيئة من أجل حماية البيئية. - تلوّتث الهواء الناتج من عو ادم السيارات يعد من أهمّ المخاطر البيئية المحدقة بالصحة.

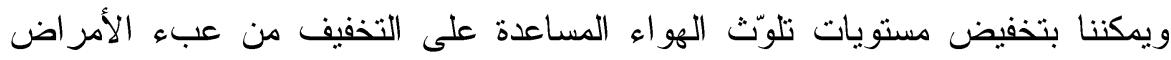

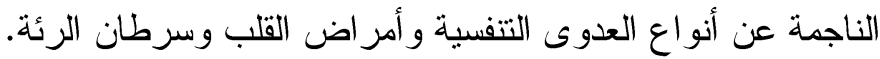

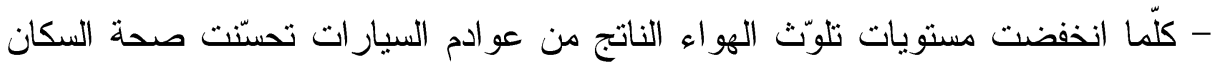
النفسية و القلبية الوعائية على المدى البعيد والقريب على حد سواء.

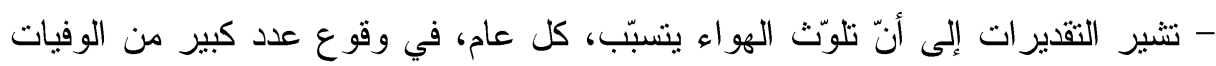
المبكرة بسبب الالتهاب الرئوي الذي يصيب الأطفال دون سنّ الخامسة.

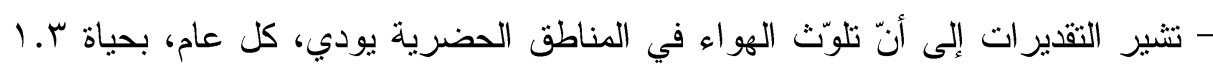

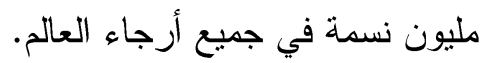

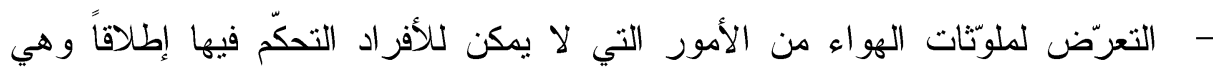

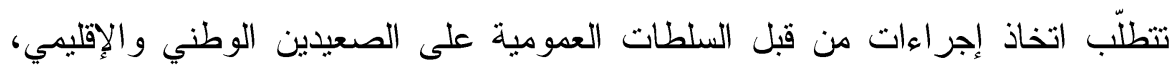
وحتى على الصعيد الدولي.

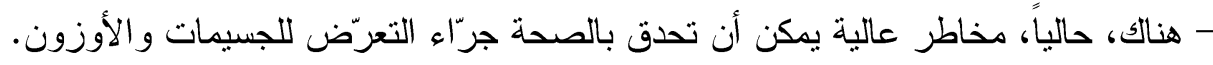
وقد بات من المككن استنتاج علاقة كية بين مستويات النلوّث وعديد من المشكلات 
الصحية متل ارتفاع معدلات الوفيات أو المرض، ممّا يمكّن من التعمّق في فهم

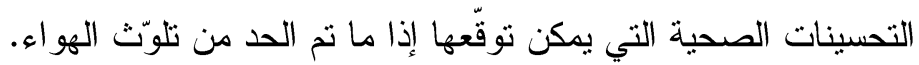

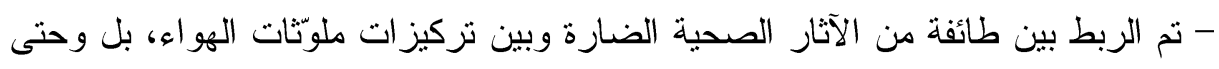
التزكيز ات المنخفضة منها نسبياً.

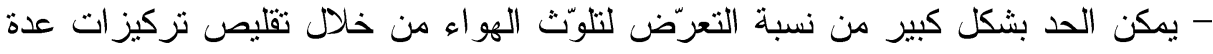

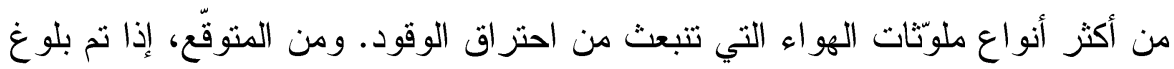

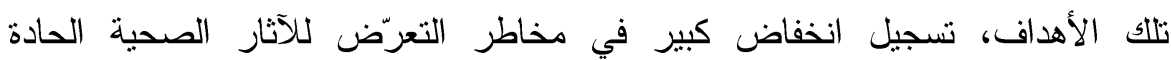

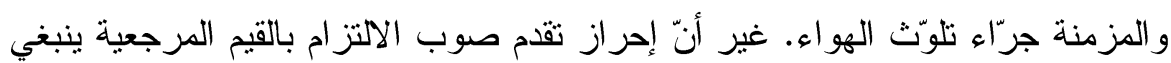
أن يكون الغرض الأسمى الذي يتعيّن تحقيقه.

\section{تموسياتي الدر اسة}

1. ضرورة التأكيد على إستيراد أو تصنيع سعه محرك السيارة بما يتفق مع الظروف

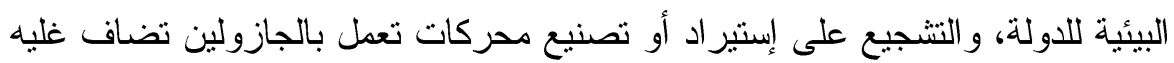
نسبة طفيفة من مركبات الرصاص. r. ضبط السبارات و الدرجات النارية الدخالفة التى تصدر عادماً بنسبة كبيرة عن النسبة

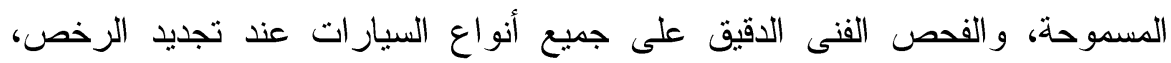

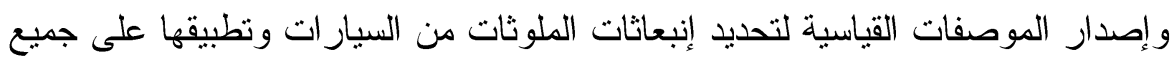
السيارات المستوردة إلى مصر بمتابعة دقيقة من الجهات المعنية

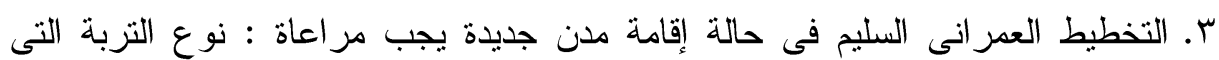

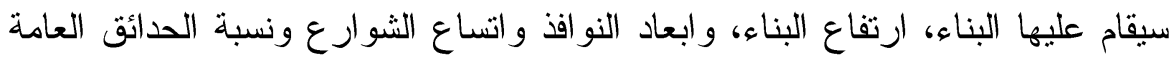

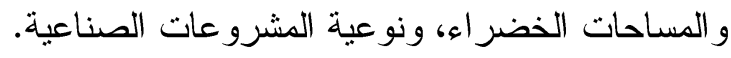
ع. التثدد فى تطبيق قانون المواصفات الخاصة بحماية البيئية من التلوث وعدم التساهل

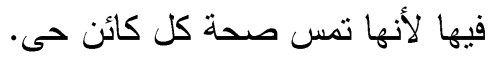


ه. تجهيز عو ادم السيارات بالمحول الحفازى، الذى يحول بعض الغازات الضاره الناجمة

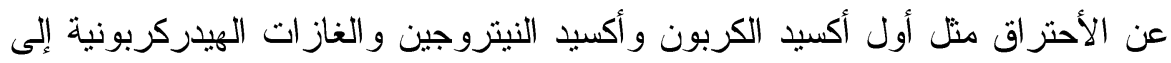
مو اد أخرى أقل ضرراً، مثل بخار الماء وثنانى أكسيد الكربون.

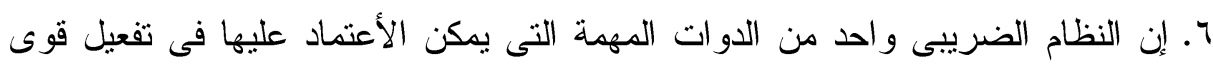

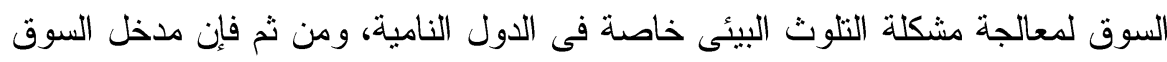
لمعالجة مشاكل التلوث البيئى يعتبر مدخلاً إسترتيجياً.

V. لقد رأى الباحث أن قياس التكاليف الخارجية فى الوحدات الإنتاجية الملوثة للبيئية أول الخطوات التى يجب غتباعها لتعديل النظام الضريبى، ليضم فى طياته الضرائب البيئية،

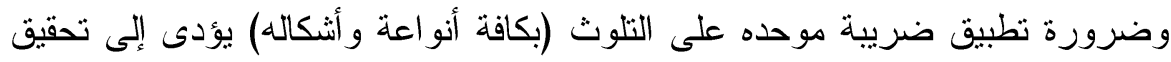
آثار ايجابية كبيرة.

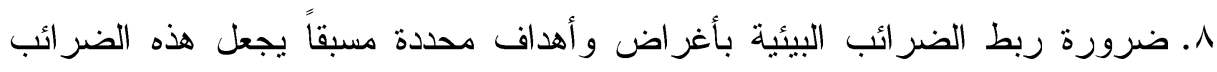

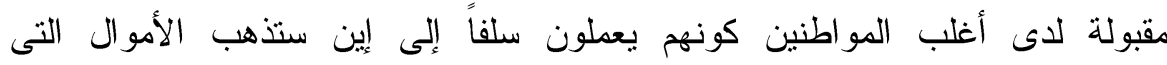

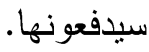
9. سن التشريعات و القوانين التى تمكن من مقاضاة المتسبب في الضرر الناتج عن التلوث

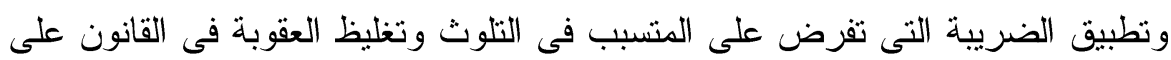
المخالفات البيئية، والالتزام بقانون حماية البيئة، وسرعة الفصل فلى القضايا البيئية،

$$
\text { وتحسين مستوى النشريعات. }
$$

• ا. تفعيل دور الأجهزة الرقابية المعنية بحماية البيئة مثل : وزارة البيئة وجهاز شئون

$$
\text { البيئة. }
$$

11. النموذج الضريبي المقترح: يرى الباحثون ان النظام الضريبي يمكن ان يستخدم لمعالجة مشكلة التلوث من خلال عاملين: معدل الضريبة و الوعاء الضريبي. 1- استخدام معدل ضريبي مقترح: يقترح استخدام معدل ضريبي مرتفع في حالة المنشات

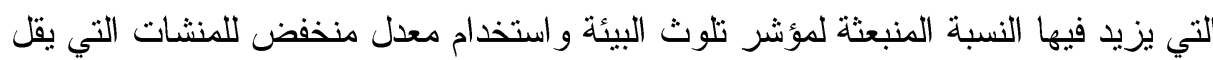
فيها هذه النسبة. 


$$
\begin{aligned}
& \text { ذللك يمكن صياغة النموذج كالاتي: ص =س + أ - ب } \\
& \text { حيث: } \\
& \text { ص: هي معدل الضريبة المقترح }
\end{aligned}
$$

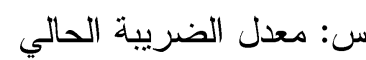

أ: معدل يضاف الى المعدل الحالي في حالة ارتفاع النسبة المنبعثة لمؤشر تلوث الهواء

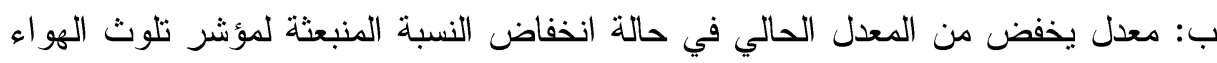
وذللك كما يلي :

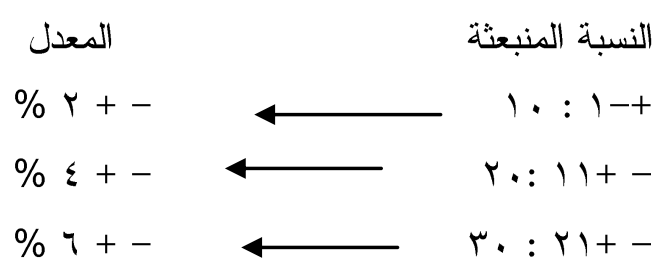

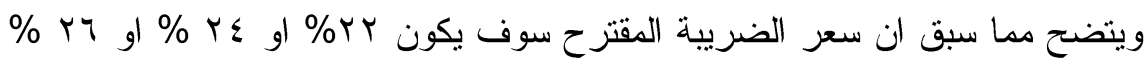

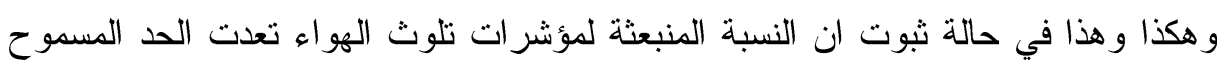

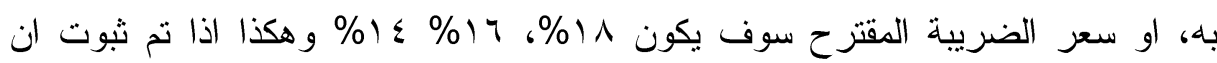
النسبة المنبعثة لمؤشر تلوث الهو اء منخفضة عن الحد المسموح به طبقا لقانون حماية البيئة

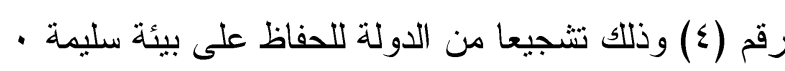
r - استخدام وعاء ضريبي مقترح: من المككن اعفاء مبلغ من الوعاء الضريبي مقابل

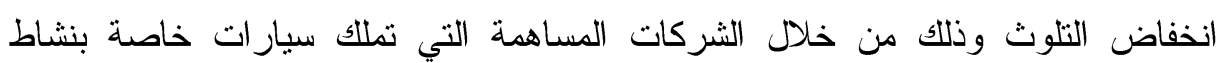
الثركة وتقدم اقرار ا ضريبيا سنويا. الو عاء الضريبي المقترح = الوعاء الضريبي للشركة + مبلغ نتيجة الزيادة فـي مؤشــر التلوث مبلغ نتيجة النقص في مؤنثر التلوث

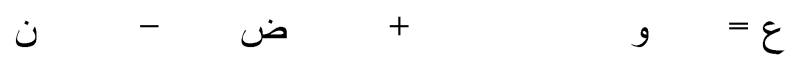

$$
\begin{aligned}
& \text { حيث: ع: الوعاء الضريبي المقترح } \\
& \text { و : الوعاء الضريبي للشركة عن النسبة الحالية }
\end{aligned}
$$


مجلة العلوم البيئية

معهد الدر اسات و البحوث البيئية - جامعة عين شمس لمس

$$
\text { ض: ضبلغ مبلغ يضاف نتيجة الزيادة في مؤشر التلوث نتيجة النقص في مؤشر التلوث }
$$

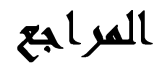

أحمد عبد السميع علام(1 . . ץ): دراسة الجدوى الفنية والاقتصادية وتقييم المشروعات، دار الوفاء لدنيا الطباعة و النشر، القاهرة

أحمد الفرج العطيات(99V (1)): البيئة الداء و الدواء، دار المسيرة للنشر والتاوزيع و الطباعة، عمان

محمد مصطفى كامل متولى(؟ (ب): استخدام مقياس القيمة الاقتصادية المضافة لتطوير مقاييس تقييم الأداء بالتطبيق على البنوك التجارية المصرية، دراسة التحة تحليلية

مقارنة، رسالة ماجستير غير منشورة، جامعة القاهرة، كلية التجارة

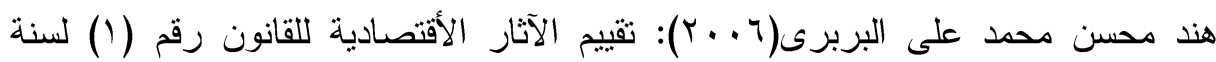
1991 (19 رسالة ماجستير، جامعة عين شمس، كلية التجارة.

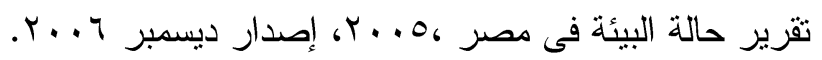

Romano Donato .2002. Notes Of The Course On "Sustaininable Rural

Develobment"fao Progect Gcp/Syr/006- Ita-

Phase.Damascus.

http//...Www. Air Polution.Com.

industry.eeaa.gov.eg

www.islamonline.net/iol-arabic/dowalia/scince

HTTP//:www.airpolution.com

HTTP//:www.airpolution.com

HTTP//:www.airpolution.com

Romano, Donato, 2002. Notes of the Course on "Sustainable Rural

Development”. FAO Project GCP/SYR/006/ITA - Phase II.

Damascus.

$$
\text { المجلد الثاني و الثلاثون، مارس } 17 \text { ـ }
$$


محمود محمد الحويحى وآخرون

Pearce, David W., and Jeremy J. War ford, 1993. World without End . Economics, Environment, and Sustainable

\title{
AECONOMICAL EVALUATION OF AIR POLLUTION INDICATORS BY EXHAUST OF MOTOR VEHICLES WITH TAX MODEL PROPOSAL AN APPLIED STUDY OF CAIRO GOVERNORATE
}

Hewahy, M. M. ${ }^{(1)}$; Ebied, S. T. ${ }^{(2)}$ and Ibrahim, Naglaa, O. M. ${ }^{(3)}$ 1) Institute of Environmental Studies \& Research Ain Shams University 2) Faculty of Commerce, Ain Shams University, 3) Egyptian Holding Company for Petrochemicals

\begin{abstract}
Introduction: Pollution resulting from human-induced Environmental conditions, thus affecting the balance of elements and components. Transportation is a major cause of air pollution in private cars powered by diesel cities. Where resulting from car exhausts of Greenhouse gases, a group characterized as colorless and with a high degree of toxicity composed.

Carbon monoxide gas is (CO) of more air pollutants in urban areas, a highly toxic gas for Humans and Animals, increase its impact on congestion and Rash-hours, which is very dangerous and cause accidents due to breathing over the years.

It is also carbon dioxide $\left(\mathrm{CO}^{2}\right)$ one of the most important causes difficulty breathing and a feeling of suffocation, and the occurrence of problems to the mucous membranes and bronchitis.

The Nitrogen oxides (No) It increases lung sensitivity to different diseases breathing is also working on the mucous membrane irritation to the eyes.
\end{abstract}

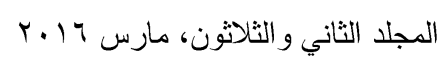




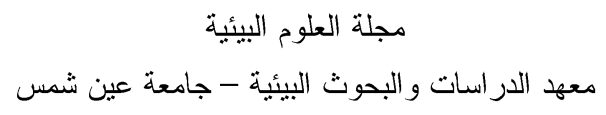

Hydrocarbons (HC), a fuel is completely burned. These materials are considered toxic substances and carcinogens.

Sulfur dioxide $\left(\mathrm{SO}^{2}\right)$ affects the respiratory tract, high concentrations of this gas lead to spasm and suffocation and the occurrence of pulmonary sclerosis.

The lead molecules causing pain in the joints and muscles, Anemia, inflammation of the peripheral nerves and kidney disease, and affects many functions of the brain.

The goal of the study: The transport and communications sector on the issue with him and what kinds of exhaust smoke source of about 70 per cent of the existing polluting gases in the air. This high rate caused by the massive increase in the production and use of cars and vehicles. Thus, the growing number of cars means an increase in the amount of exhaust gases emitted by these vehicles and determine the amount of gas emissions from the transport sector, according to the mechanisms and the size of the engines and the quality of the used fuel type. The most important air pollutants released from the transport sector are carbon monoxide and oxides of nitrogen (NO) gas and hydrocarbon (HC) and lead.

Methodology of the study: The study relied on the theoretical method that office to gather facts and information about the nature of the problem at hand is based on, and then completed in a way that the analytical description of this information in order to reach results pertaining to this matter, and which help to reach the desired goal of the research.

\section{Results:}

- Air pollution resulting from motor vehicle exhaust is one of the most important environmental risks to health.

-Whenever the air pollution from car exhaust levels decreased mental health and cardiac vascular population has improved in the long term and the short.

-Air pollution causes, every year in a large number of premature deaths due to pneumonia, which affects children under the age of five.

-Air pollution in urban areas kills, each year, the lives of 1.3 million people around the world.

- There is a high risk to health from exposure to PM and ozone.

$$
\text { المجلد الثاني و الثلاثون، مارس ب } 17
$$

